\title{
Professor Emérito Antonio Ferreira de Almeida Junior.
}

\author{
João Baptista de O. e Costa Junior \\ Catedrático de Medicina Legal na Faculdade \\ de Direito da Universidade de São Paulo.
}

Vejo-me, neste instante, em situação que me faz recordar as palavras do maior orador da lingua portuguêsa, quando, ao proferir o sermão nas exéquias do serenissimo Infante de Portugal, Dom Duarte, afirmou que era preferivel "trocar as palavras em lágrimas, e que em lugar de eu dizer e vós ouvirdes, choráramos todos". As lágrimas, continua o insuperável tribuno, são o mais vivo do sentimento, porque são o destilado da dor; são o mais encarecido dos louvores, porque são o preço da estimação; são o mais efetivo da consolação, porque são o alívio da natureza."

Douta Congregação e ilustres convidados.

Foi, quando, recém egresso da Faculdade de Medicina de São Paulo, durante o concurso para médico-legista do Estado, que vi, pela primeira vez, o Professor Almeida Júnior. Conhecia-o, entretanto, de nome, e, principalmente, pelo que fizera em pról da educação, como um dos expoentes do ensino oficial do país. Não sei porque, de todos os examinadores, era êle o que infundia maior temor; com seu trato, porém, a um tempo afável e austero, procurando em todos os momentos, aferir meticulosamente os méritos

* Discurso proferido no salão nobre, a 10 de maio dêste ano, em sessão de homenagem póstuma ao professor emérito Antonio Ferreira de Almeira Junior, no trigésimo dia de seu falecimento. 
de cada candidato, desvaneceram-se-me as preocupações iniciais pela certeza de que sua presença afiançava o resultado do concurso, o qual, acreditava eu, seria apreciado e julgado com a mais rigorosa e absoluta justiça.

Depois, regressando a São Paulo, após 7 anos de atividades no interior do Estado, onde fôra desempenhar o cargo conquistado, tive a oportunidade e a grande ventura de reencontrá-lo com bastante freqüência. Nas reuniões da Sociedade de Medicina Legal e Criminologia, onde sua palavra era acatada com o maior respeito, deslumbrando a todos, tanto pela fluência e beleza de expressão quanto pela exuberância da sua cultura profunda e variada.

Mais tarde, no tempo em que pretendi docência-livre na cadeira do emérito Prof. Flamínio Fávero, na minha Faculdade de Medicina, foi Almeida Júnior novamente meu examinador, e, aí, pude avaliar, ainda uma vez, as suas qualidades de exímio argüidor, que, por uma forma rigorosa, porém justa e humana, firmava e valorizava a tal ponto o concurso, que isso fôra motivo de justificado orgulho do candidato.

Examinou-me, todavia, o ilustre mestre, uma vez mais, quando, por ocasião do concurso para livre docente nesta gloriosa Faculdade, a sua palavra de $1 .^{\circ}$ argüidor, foi a tônica estabelecida para tôda prova, que êle sempre exigia em alto nível e sem concessões que pudessem aviltá-la, denegrindo o próprio sistema universitário. Podeis, portanto, ajuizar da ufania transbordante daqueles que tiveram a honra da participação dêsse notável mestre, nos prélios científicos das suas carreiras universitárias.

Imaginai, pois, o meu envaidecimento, ao sucedê-lo na cátedra de Medicina Legal desta Faculdade. Sentei-me, depois, a seu lado, em outros concursos, não já na situação aflitiva de candidato, mas na condição de poder manifestar todo meu entusiasmo por integrar a mesma comissão julgadora na qual Almeida Júnior emprestava relêvo invulgar. E só isso já era, para mim, um título precioso e de elevado merecimento. 
Sua vida resumiu-se, posso afirmar, sem receio de qualquer contestação, em doutrinar, preparando a mocidade da sua terra para a edificação de uma pátria grandiosa, onde houvesse amor, paz, cultura e justiça.

Quando se procura narrar, com fidelidade, a vida de alguem que a viveu intensamente, é sempre difícil o orador traduzir a riqueza de manifestações expressivas do homenageado, correndo o risco de omitir alguns aspectos importantes de sua biografia ou de tornar-se monótono, prolongando em demasia o tempo convencional da oração. é precisamente essa apreensão que vos quero alegar, já que me cabe o dever de exaltar um dos maiores vultos surgidos no magistério brasileiro de todos os tempos.

Sabemos nós que Antonio Ferreira de Almeida Júnior nasceu em Joanópolis, conhecida na época como São João do Curralinho, no Estado de São Paulo, aos 8 de junho de 1892; sendo filho legítimo do primeiro matrimônio de Antonio Ferreira de Almeida e de Otília Caparica Ferreira de Almeida. Demonstrou, desde a mais tenra idade, a sua grande inteligência, o que o levou a vencer, com extrema facilidade, todos os obstáculos escolares. Iniciou o curso primário em sua cidade natal, vindo a concluí-lo, em 1905, nesta Capital, no 2..$^{\circ}$ Grupo Escolar do Brás, hoje, Eduardo Prado.

Após um curso preparatório noturno, prestou exame de suficiência, em 1906, na Escola Normal Secundária da Praça da República, onde, em 1909, obteve o diploma de normalista. No dia 4 de abril de 1910, exatamente há 61 anos, de sua morte, iniciou a carreira no magistério oficial, galgando todos os graus e revelando-se sempre o didata capaz de atrair sem qualquer fadiga a atenção de todos os alunos. A primeira escola que o teve por mestre foi a Escola Isolada da Ponta da Praia, no município de Santos. Um mês depois foi nomeado para a Escola Modêlo Isolada, anexa à Escola Normal da Praça da República e em julho foi designado para reger a $1 .^{a}$ Série do Curso Complementar anexo a essa mesma Escola Normal. Foi professor de 
francês e pedagogia na Escola Normal Primária de Pirassununga; da primeira disciplina de 29 de marco de 1911 a 30 de agôsto de 1915, e da segunda durante apenas 8 meses, sendo, nessa ocasião, seus alunos, entre muitos outros, Lourenço Filho e Ernesto Leme.

Procurando sempre melhorar os seus conhecimentos, viajou à Europa, pela primeira vez, em 1913, quando, revelando inusitado entusiasmo pela Cidade Luz, pensou em visitá-la cada dois anos; entretanto, por motivos independentes de sua vontade, só pôde revê-la 38 anos depois.

Após pedir exoneração da Escola Normal de Pirassununga, regeu a Escola Noturna para meninos operários, instalada no então Instituto Disciplinar desta Capital.

Em 1916, tendo completado os exames do curso secundário, no Ginásio do Estado, hoje Colégio Estadual de São Paulo, e sido aprovado nos exames vestibulares, matriculou-se na Faculdade de Medicina e Cirurgia de São Paulo, onde se diplomou em 1921. Obteve o título de doutor em Medicina, aprovado com grande distinção, na defesa da tese O Saneamento pela Educação. Nesse mesmo ano, como bolsista da Fundação Rockfeller, tornou-se assistente extra-numerário do Instituto de Higiene, mais tarde transformado em Faculdade de Higiene da Universidade de São Paulo. Desempenhou, em 1919, funções de auxiliar do Diretor Geral do Ensino, e, no ano seguinte, chefiou o $1^{\circ}$ Recenseamento Escolar do Estado de São Paulo. Em fins de 1920, começou a reger a cadeira de Biologia e Higiene da Escola Normal do Brás, atual Instituto de Educação Padre Anchieta. Foi, nessa ocasião, que conheceu sua aluna Maria Evangelina de Almeida Cardoso, filha de Francisco Almeida Cardoso e de Rita Evangelina de Almeida Cardoso, com quem se casou no dia 24 de fevereiro de 1922, e de cujo matrimônio nasceu, em 29 de junho de 1923, seu único filho, Dr. Roberto Luís Ferreira de Almeida, ilustre Promotor Público nesta Capital.

Foi um dos fundadores do Liceu Nacional Rio Branco, hoje Colégio Rio Branco, tendo lecionado Física, Química 
e História Natural, e exercido, também, as funções de Diretor de 1928 a 1933, ocasião em que foram seus alunos os irmãos Rafael e Washington de Barros Monteiro.

Ainda em 1928, foi aprovado no Concurso para a docência livre de Medicina Pública, depois chamada Medicina Legal, da Faculdade de Direito de São Paulo, defendendo a tese $O$ exame médico pré-nupcial.

Em 1933 foi transferido da Escola Normal do Brás para o Curso de Aperfeiçoamento do Instituto Caetano de Campos; chefiou o Serviço de Saúde Escolar do Estado; c participou da elaboração do Código de Educação, promovida pelo Prof. Fernando Azevedo.

Nesse mesmo ano, teve seu nome aceito pelo Conselho Nacional de Educação para o cargo de professor da Cadeira de Medicina Legal da Escola Paulista de Medicina.

Participou, em 1934, da Comissão que organizou o plano da Universidade de São Paulo, e fundada esta, tomou parte na claboração dos estatutos, sendo então eleito membro do primeiro Conselho Universitário.

Integrou, de 1934 a 1941, a Congregação da Faculdade de Filosofia, Ciências e Letras da USP.

Em 1935, juntamente com outros educadores, propôs o questionário que serviu de ponto de partida para a elaboração do Plano Nacional de Educação, previsto na Constituição Federal de 1934. Ainda nesse ano, foi nomeado Diretor Geral do Ensino do Estado de São Paulo, cargo que exerceu até 1938 , tendo, então, a oportunidade de projetar um amplo programa de construções escolares, em grande parte executado.

Em 1939, foi nomeado membro do Conselho Médico Legal do Estado.

Prestou, em 1941, concurso para a cátedra de Medicina Legal da Faculdade de Direito da Universidade de São Paulo, classificando-se em primeiro lugar, tendo defendido a tese Provas Genéticas da Filiação.

Foi membro do Conselho Penitenciário do Estado de 1944 até 1969. 
Secretário da Educação e Saúde em 1945, cargo que exerceu até fevereiro de 1946. Membro e Relator Geral da Comissão que elaborou o primeiro anteprojeto da Lei de Diretrizes de Base da Educação Nacional.

De 1949 até 1957, integrou o Conselho Nacional de Educação.

Em 1955, foi nomeado membro do Conselho Estadual do Ensino Superior.

Presidiu, em 1956, a comissão que organizou o $10^{\circ}$ Congresso Estadual de Educação Primária.

Eleito, em 1959, membro do Conselho Regional de Medicina de São Paulo.

Nomeado, em 1960, membro do Grupo de Trabalho pelo Governador de São Paulo, para estudar o problema da expansâo do ensino superior no Estado.

Membro do Conselho Federal de Educação de 1962 a 1967.

Em 1962, aposentou-se na Cadeira de Medicina-Legal da Faculdade de Direito da Universidade de São Paulo e da Escola Paulista de Medicina.

Em julho do mesmo ano, foi-lhe conferido, pelo Govêrno de São Paulo, o título de Servidor Emérito do Estado. Ainda em 1962, a Escola Paulista de Medicina outorgou-lhe o título de Prof. Emérito; e, título igual, obteve da Faculdade de Direito da Universidade de São Paulo em 1964.

Possuía mais os seguintes títulos: Grande Oficial da Ordem do Mérito Educativo; doutor honoris causa pela Universidade Mackenzie; sócio titular, benemérito e honorário, da Sociedade de Medicina Legal e Criminologia de São Paulo; sócio fundador da Sociedade Paulista de História; sócio fundador da Sociedade Paulista de Medicina Social e do Trabalho; membro Emérito da Academia de Medicina de São Paulo; membro correspondente da Associação Médica Argentina - Secção Medicina Legal e Toxicologia; sócio honorário da Academia Brasileira de Ciências Médicas Sociais; sócio honorário da Associação dos 
Administradores Escolares; sócio fundador da Associação dos Cavaleiros de São Paulo; sócio honorário do Centro Acadêmico Pereira Barreto. Recebeu o Prêmio de Educação-Visconde de Pôrto Seguro em 1957 e o Prêmio Moinho Santista - no setor Ciência da Educação em 1970. Possuía, também, as medalhas Nina Rodrigues, Oscar Freire, além de várias placas de prata, oferecidas por agremiações universitárias e turmas de ex-alunos.

o Prof. Almeida Júnior realizou viagens de estudos à Europa e aos Estados Unidos, bem como, em missão cultural, ao Chile, visitando na mesma ocasião a Argentina e o Uruguai. Participou também de vários Congressos de E’ducação.

Sua produção científica em livros, teses, conferências, artigos e pareceres é volumosa, não só no campo da Medicina Legal, senão, também, nos campos da Medicina Social, Educação, Higiene, Anatomia, Fisiologia, Biologia e da Puericultura. Lembro o texto Lições de Medicina Legal, obra surgida em 1948, que logrou imediatamente grande difusão e na qual tive a honra de colaborar, a partir da $7 .^{\mathrm{a}}$ edição, sendo coautor nas edições subseqüentes. Refiro, ademais, às três teses já aludidas, com o mestre comprovando suas qualidades de investigador incansável e didata primoroso; a Paternidade (Estudo biopsicológico, social $e$ jurídico); $O$ abôrto $e$ o infanticídio no Código Penal de 1940; a Hereditariedade e o Crime; e a "Verificação da Periculosidade.

Fóra do campo da Medicina Legal assinalo a Biologia Educacional em 20. ${ }^{\text {a }}$ edição; Elementos de Anatomia e Fisiologia Humanas, na 34." edição; A Escola Pitoresca; Problemas do Ensino Superior; e Sob as Arcadas, esta última, uma coletânea de ensáios, artigos e conferências.

Destaco, portanto, em Almeida Júnior: o educador, o escritor, e o cidadão, que nele sobressaem.

Entendia a educação no seu duplo movimento: o centrifugo, que produz o amadurecimento biopsicológico, e o 
centrípeto, que incorpora ou alcança o ideal, isto é, a perfeição humana; como escritor, embelezava e divulgava sua obra educativa; e como cidadão, representava o homem, na sua mais pura concepção: o homem bom, integro, trabalhador, discreto, integrado no espírito de solidariedade social; o que, todavia, não o impedia de manifestar-se, muitas vêzes, com fina ironia, não insolente nem agressiva, mas apenas de advertência a qualquer ato que lhe desagradasse.

Posso acrescentar que Almeida Júnior foi, também, político; entretanto, tal atividade, inclusive a de presidente do Diretório Regional de uma das agremiações políticas do país, não lhe trouxe outras implicações. Foi apenas uma manifestação episódica e serviu para demonstrar que, nêle, as qualidades do político não eram diversas das qualidades do cidadão: calmo, sereno, compreensivo, incapaz de impor sua vontade com violência ou intolerância e sempre pronto para resolver as situações mais dificeis, de todos os que dêle se acercavam.

Ainda há poucos dias, ao presenciar o desencanto de uma diretora de colégio oficial de São Paulo, na luta imensa para impedir que a dignidade e a eficiência do ensino, já restabelecidas, fôssem novamente perdidas ante a corrupção, a desonestidade, a depredação, a fraude e a subverção, e, ainda o mais grave, com a conivência dos que tinham o dever de preservá-las, lembrei-lhe as seguintes palavras de Almeida Júnior :

"O ensino público está de tal forma vinculado ao meio social que não pode ser muito pior nem muito melhor do que aquilo que êsse meio normalmente comporta; e seria ilusória a esperança de vê-lo transpor de súbito a margem da variação imposta pelo ambiente. . cada um deve fazer como se a perfeição definitiva só estivesse à espera de seu esfôrço individual".

O Prof. Almeida Júnior só compreendia a vida universitária na sua pureza e autenticidade, jamais admitindo as facilidades para se tornar amável ou auferir alguma van- 
tagem. E essa conduta moral, era motivo de respeito e admiração por parte dos discípulos. Conforta-nos as palavras do estudante, na apresentação do $16 .^{\circ}$ número da Coleção XI de Agôsto, quando se refere ao ilustre professor: "Não se compatibiliza o Prof. Almeida Júnior com as estudantadas perniciosas à formação moral e intelectual dos acadêmicos; todavia, sua atitude não é a de um ranzinza, inconformado com a jovialidade dos moços. Adota o preclaro mestre, uma posição de equilíbrio e bom senso, não pretendendo extinguir as tradições acadèmicas, pelo contrário, auxiliando na sua conservação, mas procurando isentá-las de facetas menos louváveis".

A sua conferència sôbre a Patologia da Vida Acadêmica é um repositório de ética, e uma coletânea de conselhos admiráveis, que nunca poderão ser esquecidos. Procurava êle incentivar as boas normas de vida, não só acadêmica senão também social, no sentido amplo do têrmo; preferindo antes comunicar o sentimento de otimismo a respeito das possibilidades dos moços, na cooperação construtiva da sociedade, a lastimá-las apenas ante as manifestações negativas e perturbadoras das relações humanas úteis e harmoniosas. Não deixou, contudo, de atingir, também, com o seu bisturi impiedoso, o que lhe parecera, na ocasião, foco central de delinqüência do organismo social, afirmando com energia: "O que nos infelicita e amargura não é tanto a inflação ou a penúria de gêneros alimentícios, como é a pobreza do país em homens honrados, dispostos a enfrentar com seriedade os nossos problemas econômicos e sociais, e a cumprir, rigorosamente, onde quer que trabalhem, a tarefa que lhes seja distribuída. É, em suma, senhores, a carestia de homens de bem, dotados de espírito público". E, numa sintese admirável, proclama aos jovens: "não me animo. a examinar convosco as vantagens e desvantagens da articulação de um código escrito, de que constem os deveres morais dos estudantes. Um código de tal natureza está para os moços das escolas como a constituição nacional está para o povo: só terá valor e eficácia se nascer da própria consciên- 
cia daqueles a quem se destina". Que exibição notável de suas excelsas qualidades de educador emérito, por vocação e convicção!

Explica na motivação mais profunda da vida psíquica, que a recepção aos calouros feita nas academias, isto é, o trote, é tanto de caráter agressivo como erótico. E' prossegue ". $\quad$ pode ser que, como festa interna, alegre, acolhedora e civilizada, meramente evocativa de uma velha tradição, só permanecerá em nossos costumes até o fim do século".

É um verdadeiro libelo acusatório a sua crítica acêrca das "cartas de empenho" ou o patronato como se dizia no passado. Considera famigerada a reforma que institui a freqüência livre, "panacéia que se supunha destinada a curar todos os males" e que, no entanto, "tudo piorou" Ressalta a importância da convivência entre os alunos e a respectiva escola no desenvolvimento cultural, na educação cívico-social e no desenvolvimento afetivo das várias gerações. E sôbre as greves, considerava uma pandemia, cujo resultado era "a quebra das exigências escolares"

No quadro nosográfico do ensino, disse êle, "destacase uma doença crônica: a cola, cuja "entrada triunfal, em 1871 , nas escolas superiores", vem produzindo males "sôbre a formação cultural e moral da juventude brasileira".

Depois de apontar as conseqüências intelectuais e morais da cola, insiste: "a cola é o estelionato escolar, é a infância do delito de falsificação".

E quando em 1954, um reitor de Universidade Federal pretendeu acabar com a cola, suprimindo a prova escrita, Almeida Júnior falou categòricamente: "eu, por mim, não assinarei essa rendição incondicional perante a fraude". Isso porque êle sabia salvaguardar o verdadeiro valor dos alunos pela fiscalização atenta das provas. Essas palavras exprimiam uma ilimitada confiança em si mesmo. Infelizmente, acrescento, em parêntesis, a prova escrita, a mais autêntica das aferições culturais, foi eliminada até dos pró- 
prios concursos para o mais alto nivel da carreira universitária.

Não devo deixar à margem sua censura à mercância do paraninfado: indecorosa transação na ante-sala da atividade profissional! "Estranha e perigosa forma de corrupção" representada na promessa do emprêgo, no custeio da festa de formatura e tantas outras. Mas a sua preocupação não parava aí. Indagava, também, das atividades e da eficácia das agremiações estudantís, de seus aparelhos assistenciais, das bases econômicas do seu funcionamento, pedindo informações para poder avaliá-las com justiça e, sempre, com uma dose de otimismo e confiança, "esperançado na idéia de que os moços de boa formação moral, adextrados pela experiência universitária, transfundissem "sangue novo" a essas organizações não só para "derrubar muralhas" mas também para "construir a cidade do amanhã", de acôrdo com os ideais que a viessem tornar digna da própria vida humana.

Artista nato, Almeida Júnior cultuava a arte de dizer. As suas aulas resultavam da configuração harmônica dos elementos indispensáveis à composição artística: o objetivo e o ideal na coexistência equilibrada da manifestação do belo; e tudo de maneira fluente, límpida, com a simplicidade característica da verdadeira grandeza, que não se complica, nem descamba no exótico ou no rebuscado.

No estudo, na meditação e na convivência com os jovens, foi onde êle adquiriu as qualidades inigualáveis para transmitir os seus pensamentos sempre claros e convincentes. Transformava os mais áridos temas em lições interessantes e ricas de ensinamentos vários, tanto no campo cultural quanto no cívico-patriótico, não perdendo um momento, sequer, para influir na formação da personalidade jovem, porque, mestre, sempre conceituou o magistério no seu duplo aspecto: formativo e o informativo.

Qual não foi o seu contentamento ao ser inscrito, pelo Govêrno brasileiro, na Ordem do Mérito Educativo. O di- 
ploma foi, de logo, emoldurado e pôsto em local de relêvo em sua residência, por representar-lhe, penso eu, um dos maiores prêmios que poderia almejar. E quando já bastante enfraquecido pela enfermidade, que o tirou do nosso convivio, com receio de que alguém pudesse, sorrateiramente, subtrair-lhe o precioso documento, levava-o, tôdas as noites, para o quarto de dormir, julgando que assim estivesse em local mais seguro e mais diretamente sob a sua guarda. Que síntese admirável de uma vida dedicada inteiramente aos problemas educacionais pelo amor ao Brasil e à mocidade de sua terra!

Senti profundamente a sua morte como poucos, talvez, sentiram.

Quero, pois, ao finalizar esta oração de saudade, que, ao lado da tristeza, pela imensa perda, guardemos bem vivo entre nós, o exemplo edificante dêsse varão, há pouco desaparecido, e que deu uma nova dimensão ao cumprimento do dever e à realização dos interêsses nacionais.

Agradeço a Deus, disse o Padre José Vasconcelos, em carta dirigida ao ilustre mestre que se retirava do Conselho Federal de Educação, "por ter pôsto no meu caminho um dos homens mais altos e mais integros do Brasil de hoje, homem cuja lembrança será para mim de perene exemplo e estímulo. Sôbre tudo porque êste homem foi sempre e simplesmente educador".

Foi, digo eu agora, um bandeirante da formação educacional do nosso povo. Difundiu a cultura com o melhor de sua inteligência, plasmando caracteres em gerações irriquietas e ávidas de novas formas de integração social. Não pactuou jamais com os excessos; pelo contrário, buscou, nas investigações pacientes, as causas principais dos fenômenos psico-sociais. E tinha sempre uma palavra de esperança, na certeza de que a melhor solução dos casos mais difíceis, seria encontrada no processo educacional, único meio de se obter o resultado melhor e mais estável. Não cruzou jamais os braços, indiferente, assistindo o desfilar de rea- 
ções cada vez mais complicadas e incompreensíveis, mas procurava sempre resolvê-las com justiça e serenidade.

Foi, em tudo e por tudo, coerente com a sua própria vocação: educador por tendência, consciente ao chamamento incoercível de um ideal límpido e cristalino, pois não permitia que o desânimo ou o interêsse pudessem deformálo ou ofuscar-lhe o brilho. Educador foi desde a alvorada de sua mocidade até o apagar-se da chama vital ao ser recebido pelo sagrado solo paulista! E no coroamento do destino inexorável, saíu para a última morada, carregado pelos familiares e colegas, de um recinto de aula, no qual the deram por leito a mesma cátedra, onde também havia pontificado na exibição exuberante de suas imorredouras preleções, numa prova real de verdadeira identificação e de comovedora glória.

A morte de Almeida Júnior deixa-nos desarvorados, e até inconformados, ante essa fatalidade que nos feriu profundamente. Só transpondo os limites do ponderável, encontrar-se-ia sua exata explicação: a mesma com que o narrador de $A$ Epopéia das Bandeiras, ante a perplexidade e a tristeza de um menino pela morte iminente do velho e agonizante ex-professor, conta que o pai lhe explica o transcedental e "Eterno Enigma" com êste imortal soneto:

"Si "Vida" é ter a gente a Alma retida

No cárcere do corpo, de tal sorte,

Que Ela ao seu jugo, torne-se vencida.

Então. a "Vida" não é "Vida" é "Morte"!

Si "Morte" é o eximir-se a Alma do forte

grilhão da carne, alando-se, em seguida,

Para o alto céu, n'um rápido transporte...

Então. a a "Morte" não é "Morte" é "Vida"! 
Si "Vida" é d'Alma a escravidão que A humilha, Treva que envolve a estrada que Ela trilha. . Si "Morte" é a mutação da Sua sorte,

É a volta Sua, livre, à Luz perdida. .

Por que êsse apêgo que se tem à "Vida"?

Por que êsse medo que se tem da "Morte"?

E . foi assim a última viagem do Professor Emérito Antonio Ferreira de Almeida Júnior. 